\title{
Average Concentration from T1 to T2 Normalized by Body Mass Index
}

National Cancer Institute

\section{Source}

National Cancer Institute. Average Concentration from T1 to T2 Normalized by Body Mass Index. NCI Thesaurus. Code C132440.

The area under the curve over the interval from T1 to T 2 divided by the leng th of the interval and then divided by the body mass index. (CDISC) 